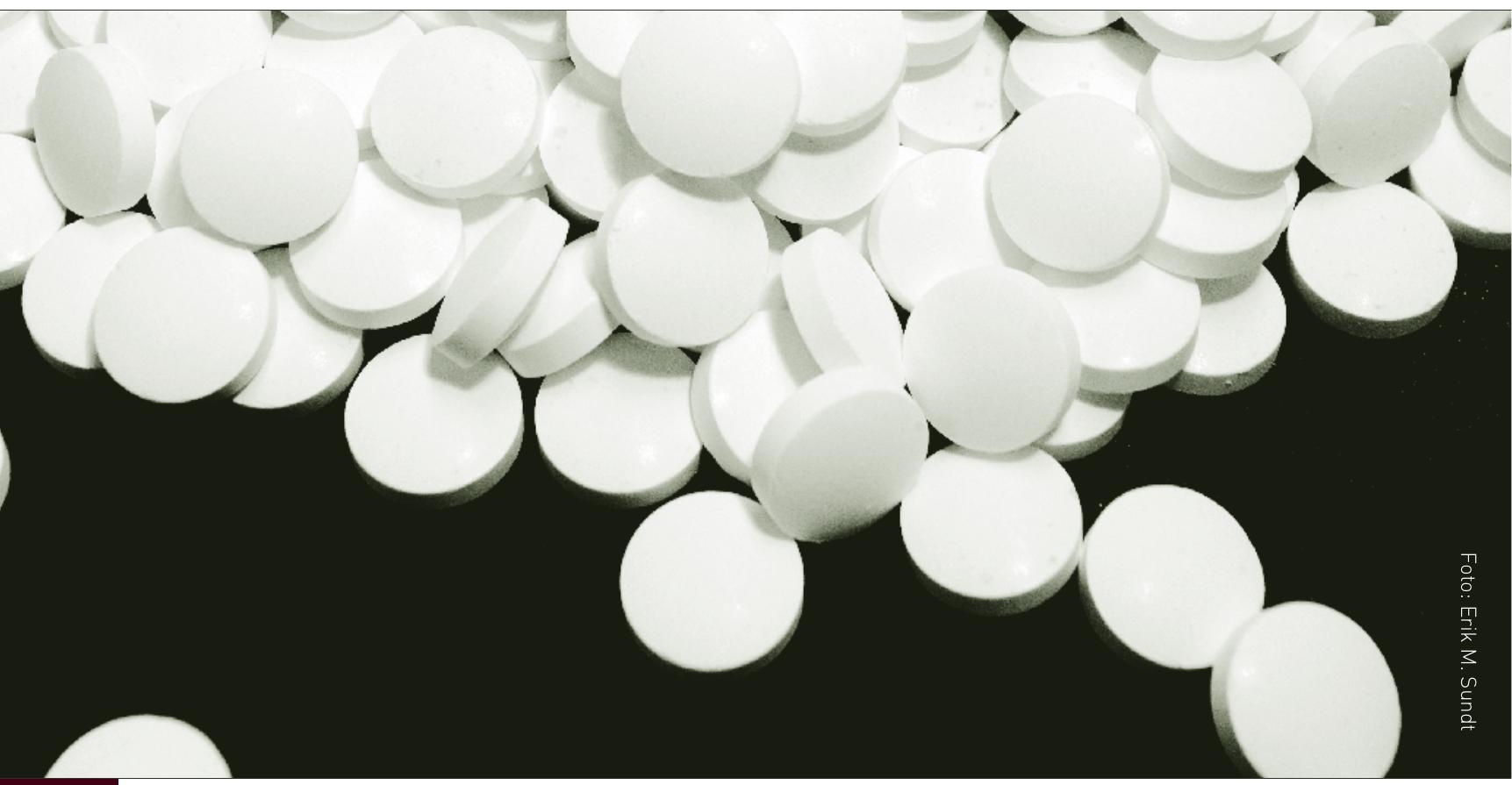

Bakgrunn: Generelle skriftlege direktiv, utarbeida av sjukeheimslegen, har vore retningsgivande for sjukepleiarane når dei skal vurdere om det skal gis behovsmedisin når legen ikkje er til stades. Det er bekymring for om variasjonen mellom og kvaliteten på slike lokale skjema går utover pasienttryggleiken.

Formål: A kartlegge innhaldet på dei generelle skriftlege direktiva ved sjukeheimar i Bergen kommune, samt kvaliteten på desse.

Metode: Dei 33 sjukeheimane i

P.r.n. medication in nursing homes - varying content, formulation and quality in administration guidelines

Background: P.r.n. administration guidelines, prepared by the nursing home physician, are used by nursing home staff when the nursing home physician is not present. Concerns are expressed that patient safety can be threatened by varying quality of these guidelines.

Objective: To describe the content and the quality of p.r.n. administration guidelines in Bergen municipality.
Bergen kommune blei bedt om å sende inn kopi av sine generelle skriftlege direktiv. Det blei deretter gjort ei innhaldsanalyse av dei innsamla direktiva ved hjelp av eit kodeskjema i SPSS.

Resultat: Til saman på dei 24 innsamla direktiva fanst det 39 ulike indikasjonar, og 51 ulike legemiddelsubstansar. Talet på indikasjonar på det enkelte direktiv låg i median på 11,5 (variasjon 3-17), medan talet på legemiddel hadde ein median på 13 (variasjon 3-21). For tre fjerdedelar av legemidla var både styrke og ei klar normaldosering oppgitt. Maksimaldosering og når ein skal kontakte lege, var oppgitt for høvesvis 61 prosent og 37 prosent av legemidla.

Konklusjon: Fleire legemiddelval per indikasjon og uklar informasjon om styrke, dosering og når ein skal kontakte lege kan gjere det vanskeleg for sjukepleiarane å ta ei avgjersle om behovsmedisinering skal gis. Samstundes kan det setje pasienttryggleiken i fare. Ei fornying av retningslinjene, samt ei meir overordna kvalitetsbetring av direktiva anbefalast.
Method: All 33 nursing homes in the municipality of Bergen were requested to send copies of their p.r.n. administration guidelines. A content analysis of the guidelines was thereafter performed using SPSS.

Results: The 24 p.r.n. administration guidelines contained a total of 39 indications and 51 medicines. The median number of indications for a guideline was 11.5 (range 3-17), and the median number of medicines was 13 (range 3-21). For three of four medicines, strength and a clear dosage were given. Maximal dosage and when the physician should be called upon were given for $61 \%$ and
$37 \%$ of the medicines, respectively

Conclusion: Several choices of medicines for each indication, and unclear information regarding strength, dosage and when to call upon the physician, can make decisions about giving p.r.n. medication difficult for nursing home staff and may threaten patients' safety. Further revision of p.r.n. administration guidelines at a managerial level is required to improve and maintain better quality.

Key words: Aged, medication systems, nursing homes, quality of health care, p.r.n. medication guidelines. 


\section{Store ulikskapar i innhald, utforming og kvalitet pà dei generelle skriftlege direktiva}

Forfattere: Lillan Mo Andreassen, Kjell Hermann Halvorsen

og Anne Gerd Granås

\author{
NøKKELORD \\ - Eldre \\ - Kvalitet \\ - Legemidler \\ - Medisinhåndtering \\ - Sykehjem.
}

\section{BAKGRUNN OG FORMÅL}

Betre legemiddelbruk i befolkninga er sett mykje fokus på $\mathrm{i}$ seinare år, blant anna gjennom Stortingsmelding nr. 18 (20042005, Legemiddelmeldinga) kor det blir understreka at uheldige konsekvensar på bakgrunn av feilaktig legemiddelbruk er mange, både for den enkelte pasient og for samfunnet (1). Ei nyleg publisert studie viser at uhensiktsmessig legemiddelbruk er eit kjent legemiddelrelatert problem i sjukeheimar (2). Same studie viser problem knytt til sjukepleiarar og anna helsepersonell sin administrasjon av legemiddel. Ein erkjenner at feil førekjem i alle ledd av legemiddelhandteringa, og at dei mest utsette pasientane er eldre menneske og ofte dei som bur i sjukeheim (1 s. 25). Vi kjenner derimot ikkje til at behovsmedisinering er undersøkt spesifikt i høve til dette.
Behovsmedisinering er bruk av legemiddel ved forbigåande plager eller ved forverring av allereie diagnostiserte tilstandar hjå ein pasient. Behovsmedisinering er ein del av legemiddelhandteringa, då denne i følgje $\mathbb{S}$ 3b) i Forskrift om legemiddelhåndtering for virksomheter og helsepersonell som yter helsehjelp, skal forståast som «enhver legemiddelrelatert oppgave som utføres fra legemidlet er rekvirert til det er utdelt» (3). I praksis tyder dette alle oppgåver som omhandlar legemiddel, frå det er bestemt kva legemiddel pasienten skal få, til han eller ho faktisk har fătt det. Uheldige hendingar knytt til legemiddelhandtering utgjer om lag 27 prosent av alle meldingar til Meldesentralen (4). Det er rimeleg å anta at ein del av desse meldingane gjeld behovsmedisinering. Det finst likevel ikkje eigne tal for dette og litteraturgrunnlaget for både bruk og administrasjon av behovslegemiddel er tynt både nasjonalt og internasjonalt.

Australske studier har vist at middel mot forstopping, smertestillande og beroligande er dei gruppene av legemiddel som oftast blir føreskrive og gitt som behovslegemiddel, men kor mykje og kor ofte ein gir behovslegemiddel er ulik frå sjukeheim til sjukeheim (5-7). Utdelinga av behovslegemiddel er ei oppgåve som er forbunde med samansette og komplekse avgjersleprosessar hjå sjukepleiarane. Til dømes speler erfaringsgrunnlag og tryggleiksaspektet i høve til både pasientar, legemiddel og prosedyrar ei stor rolle i vurderinga (8), og det er rapportert ulik praksis rundt avgjersleprosessen for, samt administrasjonen av, behovslegemiddel (9). Det kan vere vanskeleg både for legar og sjukepleiarar å vurdere kva som ligg til grunn for pasientens symptom, og om desse skal behandlast ved å gi eit legemiddel, særskilt dersom pasienten

\section{Hva tilfører denne artikkelen?}

Spreiinga i kvalitet og omfang på skriftlege direktiv for behovsmedisering i sjukeheimar, tydeliggjer behovet for ei revidering av disse både når det gjeld innhald og utforming.

\section{Mer om forfatterne:}

Lillan Mo Andreassen har master i farmasi og er doktorgradsstipendiat ved senter for farmasi, Universitetet i Bergen. Artikkelen er basert på hennar masteroppgåve. Kjell Hermann Halvorsen er cand. pharm og doktorgradsstipendiat ved Forskingsgruppe for allmennmedisin, Universitetet i Bergen. Anne Gerd Granås, cand.pharm og PhD, er tilsett som førsteamanuensis ved Senter for farmasi, Universitetet i Bergen. Kontakt: lillan.andreassendisf.uib.no 
er eit eldre menneske med ei form for kognitiv svikt.

Behovslegemiddel kan og bør helst vere tilpassa den einskilde pasient, ved å stå oppført under «ved behov» eller «eventuelt» på legemiddelkortet. I tillegg nyttast generelle skriftlege direktiv, ei skriftleg tilleggsprosedyre for generell ordinasjon av legemiddel for mindre alvorlege plager, når legen ikkje er tilstades (10). Desse brukast av sjukepleiarane i situasjonar kor legemiddelbehandling blir vurdert som nødvendig, og kor legemiddel ikkje er oppført på pasienten sitt legemiddelkort. Det er den enkelte sjukeheimslege som har vore ansvarleg for å utarbeide direktiva, sjølv om den tidlegare forskrifta om legemiddelhandtering gir somme retningslinjer for kva desse bør innehalde (11). Direktiva blir såleis ei lokal prosedyre, og vil kunne variera i utforming og innhald frå sjukeheim til sjukeheim.

I 2008 kom ny forskrift om legemiddelhandtering for verksemder og helsepersonell som yter helsehjelp (3). Fram til då har dei generelle direktiva i følgje tidlegare forskrift vore retningsgivande for sjukepleiarane når dei skal vurdere om det skal gis behovsmedisin når legen ikkje er til stades i sjukeheimen (11). Både lover og forskrifter har i seinare år bevega seg frå ei detaljregulering imot såkalla funksjonskrav (12 s. 257) og har større tolkingsrom enn regelverket dei erstattar. Den nye forskrifta for legemiddelhandtering nemner dermed ikkje generelle skriftlege direktiv og kva desse bør innehalde spesifikt. Men den slår fast i $\$ 4 b$ ) at verksemdsleiar skal «etablere og oppdatere skriftlige prosedyrer for legemiddelhåndteringen». Vidare skal, i følgje $\mathbb{7}$, 1. ledd «istandgjøring og utdeling av legemiddel til pasient skje på grunnlag av ordinering gjort av lege eller annet helsepersonell med rekvireringsrett til pasient og i samsvar med virksomhetens skriftlige prosedyrer» (3). I sjukeheimar med få legebesøk i veka, vil såleis generelle skriftlege direktiv framleis vere viktige $\mathrm{i}$ høve til behovsmedisinering.

Generelle skriftlege direktiv er òg viktige i høve til Lov om statlig tilsyn med helsetjenesten og tilhøyrande forskrift. Verksemda, i dette tilfellet sjukeheimen, pliktar å ha nødvendige og oppdaterte prosedyrar for å førebyggja svikt i helsetenesta $(13,14)$. Både lovverket og dei lokale prosedyrane, i dette tilfellet generelle skriftlege direktiv, har såleis vore viktige tiltak som skal minske risikoen for svikt innan legemiddelhandteringa. Helsetilsynet uttrykker likevel bekymring for at lokale prosedyrar og skjema er så mange og forskjellige, at dei snarare kan føre til endå fleire misforståingar og feil (4). Dei generelle skriftlege

direktiva er først og fremst eit verktøy for sjukepleiarane innanfor behovsmedisineringa, og det er viktig at dei er utvitydige og brukarvenlege.

Både den nye forskrifta og legemiddelmeldinga slår fast at farmasøytar kan nyttast som rådgjevarar i utarbeidinga og kvalitetssikringa av prosedyrane innanfor legemiddelhandteringa $(1,3)$. Ei av dei viktigaste oppgåvene til farmasøyten er å bidra til rettast mogleg legemiddelbruk i befolkninga, og utvida bruk av farmasøytar i helsetenesta er eit av satsingsområda til Helsedepartementet. Vi ønska derfor å undersøke innhaldet og kvaliteten på dei generelle skriftlege direktiva for sjukeheimar i Bergen kommune.

I retningslinjene til Bergen kommune er det omtala at direktiva bør innehalde følgjande: indikasjon, preparat, dose og forholdsreglar (10). Formålet med studien var å undersøke om

TABELL 1: Førekomst av indikasjonar på dei generelle skriftlege direktiva og tilhøyrande prosentar frå 24 sjukeheimar i Bergen kommune $(\mathrm{N}=260)$.

\begin{tabular}{lrr}
\hline Indikasjon & Frekvens & Prosent \\
Smerte & 23 & 8,8 \\
Kvalme & 23 & 8,8 \\
Forstopping & 20 & 7,7 \\
Søvnvanskar & 20 & 7,7 \\
Feber & 18 & 6,9 \\
Kramper/epilepsi & 15 & 5,8 \\
Uro/angst & 11 & 4,2 \\
Hoste & 10 & 3,9 \\
Lungeødem & 8 & 3,1 \\
Halsbrann & 7 & 2,7 \\
Diaré & 7 & 2,7 \\
Tung pust & 7 & 2,7 \\
Sterke smerter & 7 & 2,7 \\
Andre (26 indikasjonar) & 84 & 32,3 \\
Totalt & 260 & 100,0 \\
\hline
\end{tabular}


dei generelle skriftlege direktiva var utforma i tråd med retningslinjene, samt å studere eventuelle forskjellar mellom dei ulike sjukeheimane innanfor kommunen.

\section{MATERIALE OG METODE}

Alle dei 33 sjukeheimane i Bergen kommune blei per brev og seinare per telefon, bedt om å sende inn kopi av sine generelle skriftlege direktiv. Brevet var stila til den enkelte sjukeheim, og det blei opplyst om bakgrunnen til prosjektet og spesifikt kva sjukeheimane skulle bidra med. Deltakinga i prosjektet var frivillig.

Ei deskriptiv innhaldsanalyse av dei innsamla direktiva blei gjennomført, på bakgrunn av Bergen kommune sine retningslinjer, samt nokre eigne kriterium.

Følgjande blei registrert:

- Indikasjonar og tilhøyrande preparat (legemiddelsubstansar)

- Styrke

- Normal- og maksimaldosering.

- Om/når ein skulle kontakte lege

- Datering og gyldigheitsperiode.

- Namn og underskrift til ansvarleg lege

TABELL 2: Førekomsten av legemiddelsubstansar på dei generelle skriftlege direktiva ( $\mathrm{N}=301)$.

\begin{tabular}{lrr}
\hline Legemiddelsubstans & Frekvens & Prosent \\
Metoklopramid & 24 & 8,0 \\
Paracetamol & 24 & 8,0 \\
Zopiclone & 19 & 6,3 \\
Glyseroltrinitrat & 18 & 6,0 \\
Oksygen* & 18 & 6,0 \\
Diazepam & 17 & 5,6 \\
Furosemid & 16 & 5,3 \\
Bisakodyl & 14 & 4,7 \\
Morfin & 14 & 4,7 \\
Oxazepam & 13 & 4,3 \\
Andre (41 legemiddelsubstansarl & 124 & 41,2 \\
Totalt & 301 & 100,0 \\
\hline
\end{tabular}

* Oksygen er ikkje eit legemiddel, men ein medisinsk gass. Denne førekom så ofte at vi valde åta den med.
Vi nytta SPSS versjon 15.0. Ein kji-kvadrattest blei nytta for å undersøke om variablane maksimaldosering og legekontakt var uavhengige av kvarandre. Preparata blei klassifisert etter WHO's anatomiske, terapeutiske og kjemiske system for klassifisering av legemiddel (ATC-systemet) (15).

Prosjektet blei gjort i samarbeid med Sjukehusapoteka Vest, som er leigd inn av Bergen kommune til å kvalitetssikre legemiddelhandteringa ved sjukeheimane. Ingen av forskarane er tilknytt dette arbeidet til dagleg. Tilsette ved Sjukehusapoteka Vest, samt faggruppa for sjukeheimslegar i Bergen kommune fekk presentert resultata av studien då denne var avslutta.

\section{RESULTAT}

Totalt blei direktiv frå 26 sjukeheimar (responsrate 78 prosent) innsamla, kor 24 av desse blei inkludert i analysen. Dei to utelatne viste seg å ikkje vere generelle skriftlege direktiv, men ei liste over akuttmedisinske tiltak, samt eit handskrive notat om at ei generell skriftleg prosedyre ikkje

fanst ved den aktuelle sjukeheimen. Dei 24 inkluderte sjukeheimane utgjer 1479 av totalt 2173 faste langtidsplassar (16).

\section{Indikasjonar}

Kvart direktiv hadde i median 11,5 indikasjonar (variasjon 3-17), medan det til saman på dei 24 generelle direktiva fanst 39 ulike indikasjonar. Indikasjonane smerte og kvalme førekom på 23 av 24 direktiv. Deretter følgde forstopping og søvnvanskar, som fanst på 83 prosent av direktiva, og feber som fanst på 75 prosent. Det er sju indikasjonar som utgjer halvparten av det samla talet på indikasjonar for alle direktiva, medan 13 indikasjonar utgjer to tredjedelar (tabell 1). Seks av indikasjonane fanst berre på eit direktiv.

\section{Legemiddel}

Til saman på dei analyserte generelle skriftlege direktiva fanst det 51 forskjellige legemiddelsubstansar (ATC-nivå 5). Medianen for sjukeheimane var 13 legemiddelsubstansar på det enkelte direktiv (variasjon 3-21). Ti av legemiddelsubstansane fanst på 13 eller fleire av direktiva og utgjer 59 prosent av alle legemiddelsubstansane samla (tabell 2). Atten av legemidla førekom berre på eit direktiv.

ATC-gruppene analgetika (N02) og psykoleptika (N05) var like store og utgjorde samla 37 prosent av alle legemiddelsubstansar. Middel mot funksjonelle gastrointestinale lidingar (A03) og laksantia (A06) følgde etter med høvesvis 16 prosent og 14 prosent. Legemiddel innanfor desse fire ATC-gruppene utgjer til saman to tredjedelar av legemidla på direktiva.

\section{Styrke og dosering}

For dei dei legemidla som stod 
oppført på direktiva som berre fanst i ein styrke, vart styrke sett til å vere «ikkje relevant». Denne kategorien høver for 58 prosent av legemidla på direktiva. Der det er viktig at styrken er oppgitt, fanst opplysning om dette for 73 prosent av legemidla (tabell 3). For 74 prosent av legemidla på direktiva var en klar dosering oppgitt, medan for 12 prosent av legemidla var denne uklar.

Med uklar dosering meinast at det er rom for tolking av kor mykje legemiddel ein faktisk kan gi til pasienten. Eit døme på dette kan vere «1-2 Paralgin forte 3-4 gonger dagleg», medan eit døme på ei klar dosering kan vere «Ved forstopping: $10 \mathrm{ml}$ laktulose morgon og kveld». Maksimal dosering, oftast oppgitt som kor mykje ein kan gi pasienten av eit legemiddel i løpet av eitt døgn eller før ein må kontakte lege, var oppgitt for 61 prosent av legemidla. Vidare var det 37 prosent av legemidla på dei generelle skriftlege direktiva som hadde oppgitt når ein skal ta kontakt med lege. Det var ikkje nokon samanheng mellom at legekon- takt var oppgitt når maksimal dose var utelate $(\mathrm{p}=0,064)$.

\section{Datering og legeunderskrift}

Berre to av dei innsamla direktiva mangla dato, men til gjengjeld var to tredjedelar to år eller eldre. Over 60 prosent av direktiva mangla informasjon om kor lenge dei var gyldige. 79 prosent hadde påført namnet på legen som var ansvarleg for utarbeidinga, medan halvparten hadde òg påført legen sin signatur.

\section{DRøFTING}

\section{Indikasjonar}

Vi fann ingen konsensus mellom direktiva for korleis ein definerte same indikasjon. Til dømes blei brystsmerter også omtala som lungeødem og tung pust, og visa versa. Det same gjeld for indikasjonar som angst, uro og plutselege åtferdsendringar. Då desse indikasjonane i mange tilfelle bør behandlast ulikt, er det viktig at dei generelle skriftlege direktiva greier å få fram desse skilnadane. Usher et al drøfter at forskjellige helseprofesjonar kan tillegge medisinske uttrykk ulike meinin-

TABELL 3: Prosentvis førekomst av angitt styrke, dosering, maksimal dosering og legekontakt for alle legemidla på dei generelle skriftlege direktiva.

\begin{tabular}{llr}
\hline & Rangering & Prosent \\
& Ja & 31 \\
Styrke & Nei & 11 \\
$N=399 *$ & Ikkje relevant & 58 \\
& Ja & 74 \\
Dosering & Nei & 14 \\
N=399* & Uklar & 12 \\
& Ja & 58 \\
Maksimal dosering & Nei & 39 \\
N=260** & Uklar & 3 \\
Legekontakt & Ja & 37 \\
N=260** & Nei & 63 \\
\hline * Legemiddelsubstanser (ATC-niva 5). & &
\end{tabular}

gar, noko som igjen kan føre til ulik medisinering av same tilstand (9). Uklare oppfatningar av indikasjonar på dei generelle skriftlege direktiva vil med andre ord kunne redusere tryggleiken for sjukepleiarane rundt bruken av direktiva, samt auke risikoen for legemiddelrelaterte problem bland pasientane. Samstundes stiller vi spørsmål ved fleire av indikasjonane, og om dei bør finnast på dei generelle skriftlege direktiva. Døme på dette er indikasjonar som lågt og høgt blodsukker, epilepsi og kjent hjertekrampe. Desse bør i utgangspunktet inn under behovsmedisinering på den enkelte pasient sitt legemiddelkort. Utfordringane rundt dette er i stor grad bestemt av legedekninga ved sjukeheimen.

Legetenesta ved den enkelte sjukeheim er forskjellig organisert - til dømes har nokre tilgang på lege store delar av døgeret, medan andre berre har dette ein gong i veka (17). Talet på legetimar per pasient vil dermed vere forskjellig, og dette kan innverke på føreskrivinga av både faste legemiddel og behovslegemiddel (18). Færre legetimar gjer at legen ikkje i like stor grad kan følgje opp nyoppståtte behov hjå pasientane, og fleire indikasjonar kan bli sett opp på dei generelle skriftlege direktiva for å bøte på dette. Samstundes kan dette bli problematisk då pasienten kanskje ikkje får legemiddel sjølv om han treng det, og i nokre tilfelle kan legen velje å setje ein pasient på legemidlet fast for å sikre at det blir gitt (8).

\section{LEGEMIDDEL, STYRKE OG DOSERING}

Variasjonen i talet på legemiddel på det enkelte direktiv følgjer variasjonen i talet på indikasjonar, medan det totale talet på legemiddelsubstansar er noko høgare enn det totale talet for 
indikasjonar. Dette skuldast fleire legemiddelalternativ ved nokre indikasjonar. I tillegg er ulike salsnamn, formuleringar og styrkar oppgitt, samt at doseringa er uklar for fleire av desse. Til dømes kan ein ved ein av sjukeheimane velje om ein skal gi diazepam, eit beroligande legemiddel, som tablettar (Vival) eller rektalvæske (Stesolid) ved uro hjå pasienten. Vidare er doseringa tydeleg oppgjeven for administrering av rektalvæske - «2 ml Stesolid 2,5 mg/ $\mathrm{ml}$ gis rektalt, kan gjentas etter 15 minutt før ein kontaktar lege». For administrering av tablettar blir vurderinga meir utfordrande: « $2 \mathrm{mg}-5 \mathrm{mg}$ per os, kan gjentas etter 4-6 timar».

Med fleire legemiddel å velje blant, samt det høge talet på indikasjonar, aukar kravet til kunnskapar hjå sjukepleiarane. Dersom indikasjonane og doseringsinformasjonen i tillegg ikkje er eintydige, vil somme sjukepleiarar kvi seg for å gi behovslegemiddel i det heile (8). Sjølv om nokre legemiddel berre finst i ei styrke, bør denne likevel oppgjevast for å gjere det til en vane at styrke alltid skal sjekkast før administrering.

\section{Datering og legeunderskrift}

Bergen kommune sine retningslinjer for legemiddelhandtering seier at generelle skriftlege direktiv skal revurderast årleg og at kor lenge dei er gyldige må vere påført (10). Fleirparten av direktiva avviker dermed frå denne anbefalinga på begge punkt. Eit problem med gamle direktiv er at dei kan innehalde legemiddel som ikkje finst lenger, til dømes Tuxi hostemikstur og Primperan kvalmestillande tablettar. Begge desse blei avregistrert i høvesvis 2007 og 2006. Det er ikkje nødvendigvis openbert for sjukepleiarane kva som er alternativet, og dei skal heller ikkje påleggast ansvaret for å vurdere dette.

Nyare dato på direktiva gjer òg at sjukepleiarane kan vere tryggare på at legen har vurdert indikasjonar, legemiddel og dosering på direktivet i høve til dei pasientane som no bur i sjukeheimen. Informasjon om kva lege som har utarbeida og godkjent direktivet bidrar til å ansvarsgjere den aktuelle legen, både med tanke på revidering og at den informasjonen som er gitt er korrekt.

\section{Implikasjonar for sjukepleiepraksis}

$\mathrm{Vi}$ meiner at dei generelle direktiva har ein rettmessig plass i sjukeheimane. Eit direktiv av god kvalitet vil vere eit bidrag til rettare legemiddelbruk i sjukeheimen, samt eit nyttig arbeidsverktøy for sjukepleiarane når legen ikkje er tilstades. I høve til Bergen kommune sine retningslinjer for kva dei generelle skriftlege direktiva bør innehalde, var det derimot fleire av direktiva som ikkje oppfylte kriteria til fulle.

Klargjering av indikasjonar og avgrensing i talet på legemiddel er viktig for å hjelpe sjukepleiarane å velje rett type legemiddel for pasienten. Til dømes vil berre eitt valhøve for kvar indikasjon støtte sjukepleiarane si avgjersle samt auke tryggleiken for pasientane. Å unnlate og oppgjeve styrke blir først problematisk når eit legemiddel finst i fleire styrkar, men kan samstundes vere ei kjelde til undring hjå dei som skal administrere legemidlet.

I tillegg må informasjon om dosering og når ein skal kontakte lege vere på plass og vere så klar som mogleg. Maksimaldosering er viktig å ha med då det sikrar at pasienten korkje blir under- eller overdosert. Ved manglande effekt etter maksimal dosering vil ein òg kunne forstå at ein bør varsle lege eller setje inn andre tiltak. Ved å ha med klar informasjon om når ein skal kontakte lege, sikrar ein pasientane best høve til å få rett behandling. Samstundes vil dette klargjere for sjukepleiarane når legen skal kontaktast ved eventuell terapisvikt. Både sjukepleiarar og legar meiner at det er viktig at det finnast klare og tydelege retningslinjer for korleis ein skal bruke direktivet, for at det skal tene sitt formål - å vere ein «tryggleiksventil» i legemiddelhandteringa (8).

Det kan vera ein god idé med den nye forskrifta frå 2008 på plass (3), at verksemdsleiar vurderer retningslinjene. Farmasøytar har gjerne ei rådgjevarrolle for fleire sjukeheimar innanfor same kommune, og tileignar seg kunnskap på tvers av desse. Farmasøytar med desse erfaringane kan nyttast som ein ressurs for å utarbeide generelle skriftlege direktiv som inneheld det beste frå dei ulike sjukeheimane. Innspel frå eit slikt samarbeid er viktig for å gi betre arbeidsverktøy for sjukepleiarane, slik at dei kan handtere behovsmedisinering best mogleg.

Bergen kommune har gjennom mange år støtta forsking i sjukeheimar kor ein har fått fram kunnskap om manglar innan omsorg (19), kvalitet (20) og legemiddelbehandling (21). Men, god forsking må følgjast opp av implementering. Vår studie gjev nokre viktige innspel til korleis en del av legemiddelbehandlinga kan kvalitetsbetrast.

\section{Styrker og avgrensingar med studien}

Studien har ein responsrate på 78 prosent, noko som gir eit godt grunnlag for samanlikning av dei generelle skriftlege direktiva. Spreiinga i sjukeheimstorleiken i Bergen kommune tilseier at 
resultata kan vere representative for andre sjukeheimar i landet. Retningslinjene frå kommunen om kva direktiva bør innehalde er ganske generelle, særskilt om ein samanliknar dei med krava i tidlegare forskrift om legemiddelhandtering (11). Dette er med på å styrke validiteten av kodeskjemaet vi utvikla og brukte. Sjølve kodinga blei ikkje vurdert av andre enn forskargruppa. Men korkje sjukeheimslegane eller farmasøytane som fekk presentert resultata frå studien ga tilbakemeldingar på at variablane eller måla vi hadde brukt ikkje var dekkande. Ein del blei overraska over dei negative resultata, då det er lagt mykje arbeid i å betre direktiva. Samstundes var begge faggruppene positive til å bruke arbeidet som ei støtte i utviklinga av betre retningslinjer og direktiv i framtida.

Av 33 sjukeheimar i Bergen kommune, svarte fire at dei ikkje hadde direktiv, tre svarte ikkje, og to bidrag blei forkasta då dei ikkje var direktiv. For dei resterande 24 direktiva hadde vi ingen måte å sikre at siste godkjente versjon var den som kom oss i hende. Vi ser det likevel som svært lite sannsynleg at sjukeheimane skulle sende oss noko som dei ikkje brukte på det aktuelle tidspunktet.

Tidlegare studiar har konkludert med at sjukeheimen i seg sjølv er det som innverkar mest på bruken av behovsmedisinering $(6,7,22)$. Vi har ikkje i denne studien sett på om det er tilhøve ved den enkelte sjukeheim som direkte påverkar innhald, utforming og kvalitet på direktiva. Vi har heller ikkje sett på kva som faktisk gis av behovslegemiddel. Ei vidareføring av denne studien vil være ei kartlegging av dette.

\section{KONKLUSJON}

Vi meiner at eit direktiv med for mange indikasjonar eller legemiddel ikkje er av det gode. Sjølv om direktivet skal ta høgde for pasientsamansetninga på sjukeheimen, må det ikkje omfatte så mange indikasjonar og legemiddel at pasienttryggleika kjem i fare. Spreiinga i kvalitet og omfang tydeliggjer behovet for ei revidering av både innhald og utforming av generelle skriftlige direktiv i sjukeheimar.

Takk til Hanne T. Fauskanger, Avdeling for farmasøytiske tenester, Sjukehusapoteka Vest og sjukeheimane $i$ Bergen som bidrog $i$ studien.

\section{LITTERATURLISTE}

1. Helsedepartementet. Stortingsmelding nr. 18/2004-2005. Rett kurs mot riktigere legemiddelbruk (Legemiddelmeldinga). 2005.

2. Halvorsen $\mathrm{KH}$, Ruths $\mathrm{S}, \mathrm{Granas} A \mathrm{G}$ et al. Multidisciplinary intervention to identify and resolve drug-related problems in Norwegian nursing homes. Scand J Prim Health Care 2010; 28: 82-8.

3. Forskrift om legemiddelhåndtering. Forskrift av 3. april 2008, nr. 320 Forskrift om legemiddelhåndtering for virksomheter og helsepersonell som yter helsehjelp. Oslo: Helse-og omsorgsdepartementet 2008.

4. Helsetilsynet. Tilsynsmelding 2007 Oslo, 2008

5. Snowdon J, Day S, Baker W. Audits of medication use in Sydney nursing homes. Age Ageing 2006; 35: 403-8

6. Stokes JA, Purdie DM, Roberts MS Factors influencing PRN medication use in nursing homes. Pharmacy World \& Science 2004; 26: 148-54.

7. Roberts MS, King M, Stokes JA et al. Medication prescribing and administration in nursing homes. Age Ageing 1998; 27: 385-92.

8. Andreassen LM. Helsepersonells erfaringer, tankar og haldningar til behovsmedisinering i sjukeheimar. Masteroppgåve Senter for farmasi, Universitetet i Bergen, 2009

9. Usher K, Lindsay D, Sellen J. Mental health nurses> PRN psychotropic medication administration practices. J Psychiatr Ment Health Nurs 2001; 8: 383-90.

10. Bergen kommune. Retningslinje for legemiddelhåndtering i sykehjem i Bergen kommune. BKDOK-2004-00640.04. Bergen 2006.

11. Forskrift om legemiddelforsyning i helsetjenesten. Forskrift av 18. november 1987, nr. 1153 Forskrift om legemiddelforsyningen mv. i den kommunale helsetjeneste. Oslo: Helse- og omsorgsdepartementet 1987.

12. Bakken K, Granås AG. Samfunnsfarmasi: legemiddelbruk og farmasøytisk profesjonsutøvelse. Fagbokforlaget, Bergen. 2010.

13. Lov om statlig tilsyn med helsetjenesten. Lov av 30. mars $1984 \mathrm{nr}$. 15 Lov om statlig tilsyn med helsetjenesten. Oslo: Helse-og omsorgsdepartementet 1984.

14. Internkontrollforskrift i sosial/helsetjenesten. Forskrift av 20. desember 2002, nr. 1731 Forskrift om internkontroll i sosial-og helsetjenesten. Oslo: Helse-og omsorgsdepartementet 2002

15. WHO. The Anatomical Therapeutic Chemical Classification System with Defined Daily Doses (ATC/DDD). http:// www.who.int/classifications/atcddd/en/ (30.12.2008)

16. Avdeling for Farmasøytiske Tjenester (AFT). Geografisk fordeling av syke-og aldershjemsplasser i Bergen pr. 31.12.07. Bergen 2008.
17. Waaler HM, Nilsen J, Nasjonalt geriatriprogram. Legetjenester i sykehjem: en nasjonal kartlegging 1999 : et prosjekt gjennomført på oppdrag av Statens helsetilsyn og planlagt og finansiert av Nasjonalt geriatriprogram (kap. 670 post 62). Oslo: Statens helsetilsyn, 1999.

18. Kersten H, Ruths S, Wyller TB. Farmakoterapi i sykehjem. Tidsskr Nor Laegeforen 2009; 129: 1732-5.

19. Husebø BS, Husebø S. Sykehjemmene som arena for terminal omsorg - hvordan gjør vi det i praksis? Tidsskr Nor Laegeforen 2005; 125: 1352-4.

20. Nygaard HA, Jarland M. Are nursing home patients with dementia diagnosis at increased risk for inadequate pain treatment? Int J Geriatr Psychiatry 2005; 20: 730-7.

21. Ruths S, Straand J, Nygaard HA. Multidisciplinary medication review in nursing home residents: what are the most significant drug-related problems? The Bergen District Nursing Home (BEDNURS) study. Qual Saf Health Care 2003; 12: 176-80.

22. Schmidt I, Claesson CB, Westerholm $B$ et al. Resident characteristics and organizational factors influencing the quality of drug use in Swedish nursing homes. Soc Sci \& Med 1998; 47: 961-71.

Les kommentaren på side 53 $>$ 